\title{
OPTIMIZATION OF OPERATIONALITY THRESHOLDS USING A MANEUVER SIMULATOR. CASE STUDY: FLOATING GATE AT CAMPAMENTO SHIPYARD
}

\author{
Miguel Cabrerizo-Morales ${ }^{1}$ Rafael Molina ${ }^{1}$, Francisco de $\operatorname{los}_{S^{2}} \operatorname{santos}^{2} \&$ Alberto Camarero ${ }^{3}$ \\ Floating structures elements are part of complex systems in which climatic agents, those derived from human \\ interaction during use and exploitation and freedom constraints are applied. Such complexity requires different \\ analysis techniques for its comprehension This paper presents a methodology to define and optimize operationality \\ thresholds of floating structures using a global scaled simulator in which all agents and system's responses are \\ modeled during a complete operational process.
}

Keywords: operationality thresholds, floating structures, simulator, floating gate, physical modeling

\section{INTRODUCTION AND MOTIVATION}

Floating structures are widely used in port and ocean engineering. They are also present in any activity related to marine structures, dock's or lock's gates, barges, floating cranes, floating terminals or vertical caisson for breakwater construction are just some examples. Even though these uses for floating bodies can be very different, most of the difficulties related to their use and exploitation are closely related. They are all part of a very complex system in which the agents are those called climatic (wind, waves and currents) but are also exposed to those derived from the use they were designed for. In addition to this, the reactions of floating bodies to such demands are frequently constrained by mooring lines, fenders or even the sea bed. All these interrelations make very difficult the comprehension and prediction of the response of such systems.

One of the main reasons to study such structures is the need to establish a threshold for one, or more, agents under which the operation of the floating facility is safe and profitable. It is very common to define operativity thresholds after an iterative process of analytical and then numerical analysis (Terencio,2011) and once this has been accomplished, those threshold are revised during normal operation of the floating structure. Such revision usually represents a higher level of operationality and therefore an increase in the operator's profits. Works as the one described in (DELTARES,2008) come closer to the optimal threshold by means of a physical model in which most of the agents and operation conditions are modeled. But there was still room for an improvement (Cabrerizo, 2007)

Therefore the principal aim of this study is to develop the methods and tools to achieve a deep knowledge of those floating systems and obtain capabilities to optimize their operationality thresholds by modeling not only climatic agents, but also those derived from the use and exploitation during a complete operation in a single test. A secondary objective has been to design and implement a global scaled simulator (1:22) in which all factors and agents are present; this includes climatic agents, those derived from operational design, operator's immediate decisions and every aspect related to human interaction.

\section{METHODOLOGY}

In order to fulfill the objectives, the proposed methodology is the following:

- Analytical study of the complete system, including climatic agents, free floating body dynamics and possible freedom constraints

- Design an instrumental setup for lab and field monitoring

- Characterize simultaneously the response of the system and operational and climatic agents in the area of operations. Following the methodology presented by Cabrerizo (2007).

- Design,construction and calibration of the physical simulator.

- Operationality analysis and threshold establishment.

\section{IMPLEMENTATION}

Due to an agreement between the Port Authority of Bahía de Algeciras (APBA) and the Harbor Research Laboratory at Technical University of Madrid, the system has been implemented for the study case of the floating gate at Campamento's Drydock.

\footnotetext{
${ }^{1}$ Harbour Research Laboratory, Technical University of Madrid, Profesor Aranguren s/n, Madrid, 28040, Spain

${ }^{2}$ Port authority of Bahia de Algeciras (APBA), Avda. de la Hispanidad, 2, Algeciras,11207, Spain

${ }^{3}$ Civil Engineering \& Transport Dept., Technical University of Madrid, Profesor Aranguren s/n, Madrid, 28040, Spain
} 


\section{Case study: Floating gate at Campamento's Shipyard}

Campamento is located in the north-east side of Algeciras Bay, close to Gibraltar strait. The shipyard was developed in the 70' to build very large LNG carriers as a strategic response to conflicts and political instability of the Persian Gulf. The facilities included a 400 meter long and 50 meter wide dry-dock with a draft of 9 meters. The closure of the basin was achieved by placing and sinking a floating caisson at the entrance, performing the inverse procedure to open the dock.(Figure 1)

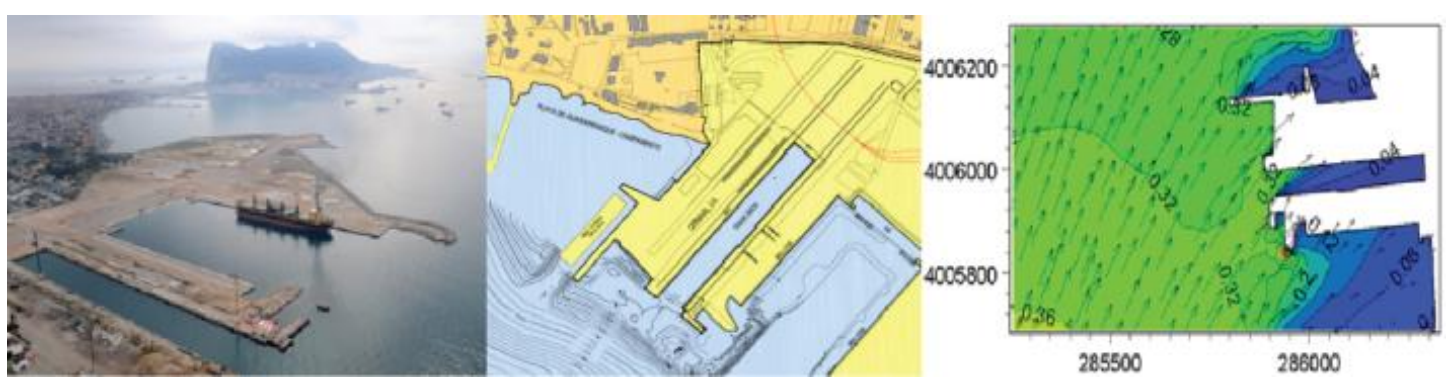

Figure 1.- Left: Aerial view of the shipyard; Center: Dry-dock layout and bathymetry (North up); Right: Mean wave conditions in the area

Due to political reasons the project was abandoned and the facilities remained unused until mid nineties. In 1996 Astilleros Cernaval became the operator of the dry-dock and performed its conversion to ship repair duties. In the former project not more than one or two opening/closing operations were expected along a year (APBA). Nowadays the shipyard is providing services to 100 to 150 ships per year; although not all of them are in need of the floating gate, the number of operations of the floating caisson required has been increased by a factor of 50 (once per week). This new operational condition means that it is no longer feasible, or profitable, to wait for calm weather window in order to open the dock. The floating gate in which this project is based is a 4300 ton concrete caisson whose length over all is 52 meters, beam is 12 meters and has a depth of 11.5 meters. During a normal operation the caisson is set afloat by pumping out the water ballast, then It's pulled from the dock entrance to a garage area by means of three winches. After the ship has been berthed or taken out of the dock the caisson is pulled back in to the closure and sunk in place. Those displacements are performed with only 0,5 meter of free draft so any minor heave, pitch or roll could developed in failure

To apply the mentioned methodology to Campamento's Floating Gate the following procedures have been followed:

1. Analysis of the entire system in order to identify possible operational failure modes (Losada, 2001) and define instrumental setup for a correct characterization of the agents and responses. For this particular case, the interest is focused in collisions between the floating gate and the surrounding structures due to roll, pitch, yaw, heave, sway or surge.

2. Design and implementation of tools capable of monitoring the response of the system to agents both on field and in the laboratory. In order to easily correlate laboratory and field data a single measuring technique is used to monitor the six degrees of freedom of the floating body. Following the works of (Molina, 2007) and (Matutano et al. 2011) video-image techniques requiring only one point of observation have been used. The method requires an array of targets to be deployed on the surface of the floating element under a referenced location (Figure 2. Target array for videoimage techniques on a solid. Calibration of the floating gate's inertial parameters.Figure 2). 


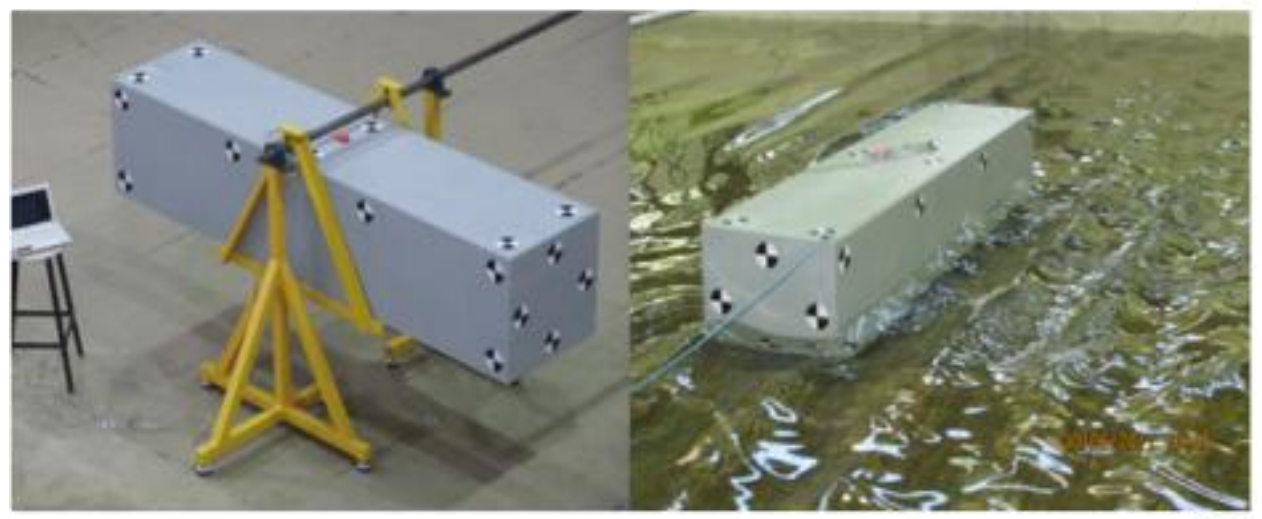

Figure 2. Target array for video-image techniques on a solid. Calibration of the floating gate's inertial parameters.

3. Carry out a series of field campaigns to characterize simultaneously the response of the system and operational and climatic agents in the area of operations. A complete list of the instruments and registered variables can be found in table1.

\begin{tabular}{|c|c|}
\hline Instrument & Variable (Unit) \\
\hline Gyroscope & Roll $(\stackrel{\circ}{)})$, Pitch $(\stackrel{\circ}{)})$, Yaw $\left(^{\circ}\right)$ \\
\hline Accelerometer & $\operatorname{Acc} X\left(m / s^{2}\right), \operatorname{Acc} Y\left(m / s^{2}\right), \operatorname{AccZ}\left(m / s^{2}\right)$ \\
\hline Video-Imagery & $\operatorname{Roll}\left({ }^{\circ}\right)$, Pitch $\left({ }^{\circ}\right)$, Yaw $\left({ }^{\circ}\right)$, Heave $(m)$, Sway $(m)$, Surge $(m)$ \\
\hline ADCP/AST & $\operatorname{Uc}(\mathrm{m} / \mathrm{s}), \mathrm{H}(\mathrm{m}) \mathrm{T}(\mathrm{s}) \operatorname{Dir}(\stackrel{\circ}{)})$ \\
\hline Press. Gauges & Ballast level (m) \\
\hline Dynamometers & Mooring line force $(\mathrm{KN})$ \\
\hline
\end{tabular}

Besides those instruments intended for monitoring of agents and responses, accelerometers are used to identify collisions between the floating gate and the surrounding structures. Figure 3 shows the layout of the operational area as well as the instrumental set up.

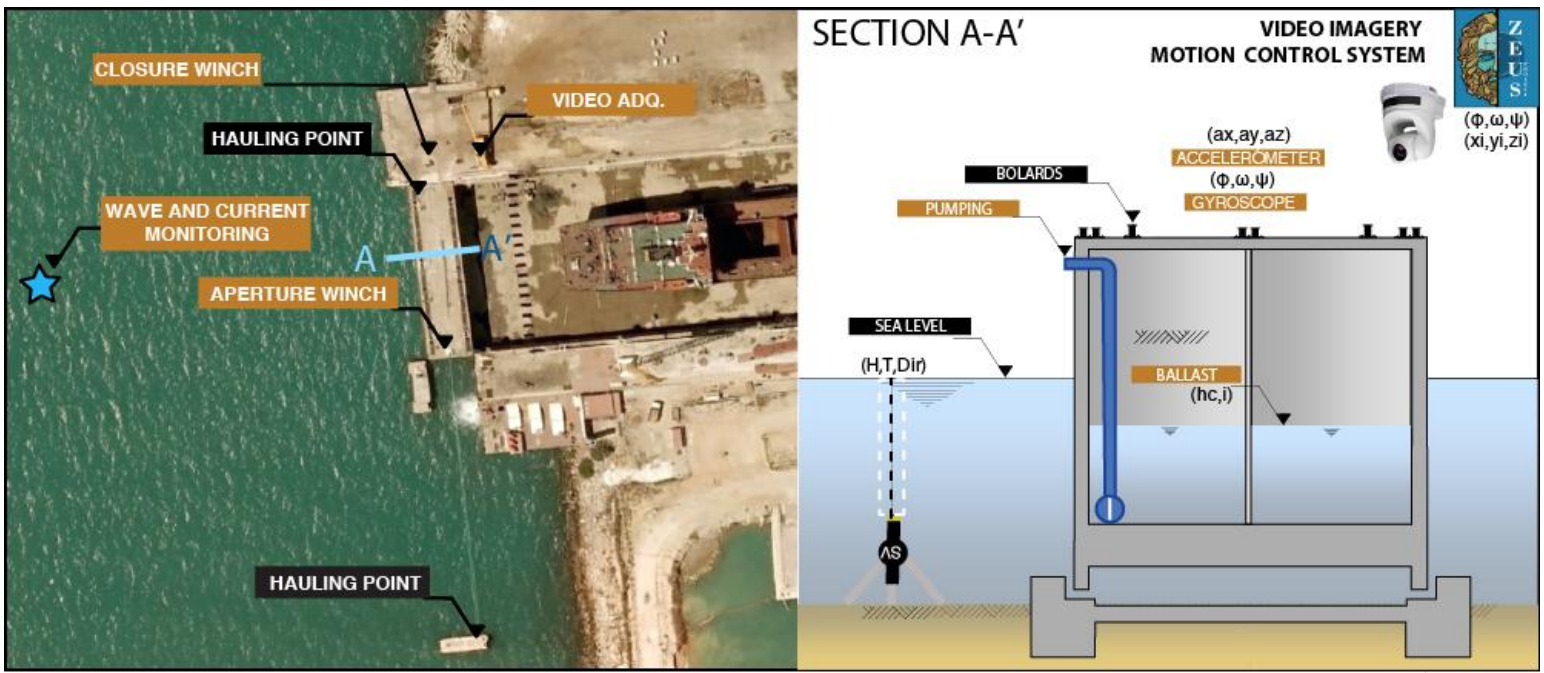

Figure 3. Layout of the instruments used to monitor agents and system responses during operation of the gate. Cross-section A-A' of the gate showing the variables involved.

4. To develop a field study of the rig/maneuvering setup and all the procedures carried out by the crew. As it has been stated before, human interaction and mooring rig set up can be responsible of 
great differences in the response of the floating gate to climatic agents. For this reason, a complete and synchronized log is taken of all the activities and orders executed by the crew.

5. Design and construction of the physical simulator, including a wireless real time monitoring and control system. The physical model for the simulator was built in the wave basin at the Harbour Research Laboratory at Technical University of Madrid. The facility is 32 meters long, 11 meters wide and has a total depth of 1.3 meters. The basin is equipped with a multidirectional wave generation system equipped with dynamic wave absortion. The selected scale is 1:22. Boundary conditions and proper control of reflection are crucial when modeling floating elements (Chakrabarty,S.K., 1994), for this reason ether based polyurethane foam was used (Cabrerizo et al. 2010) as it can be seen in figure 4

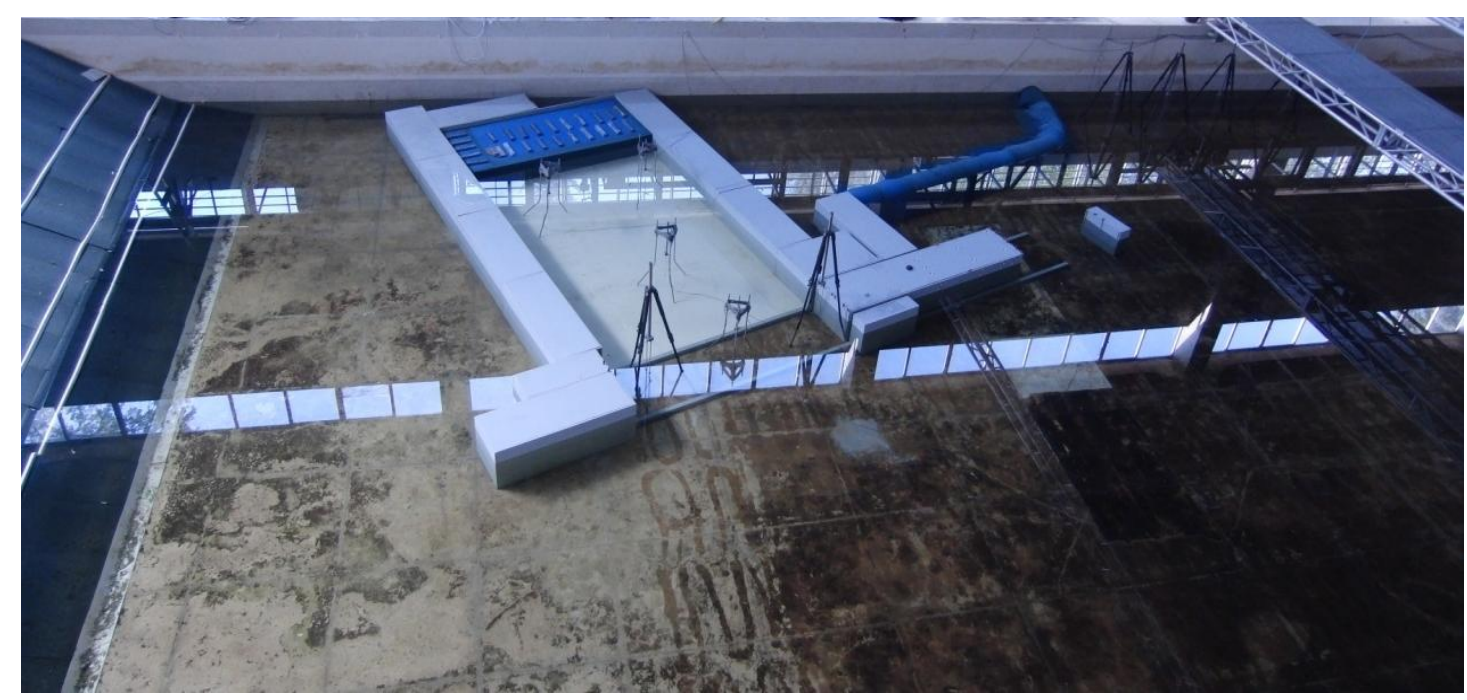

Figure 4. Simulator layout in HRL-UPM 3D Wave Basin. Note blue polymer foam for wave reflection control.

Control of the simulator as well as monitoring of the measured variables is achieved using Small scale Real time Caisson Monitoring and Control System (SRECMOCOS). The system is divided in two synchronized modules, a control and communications module and a web-based data management tool (figure 5) that allows remote access to simulation data.

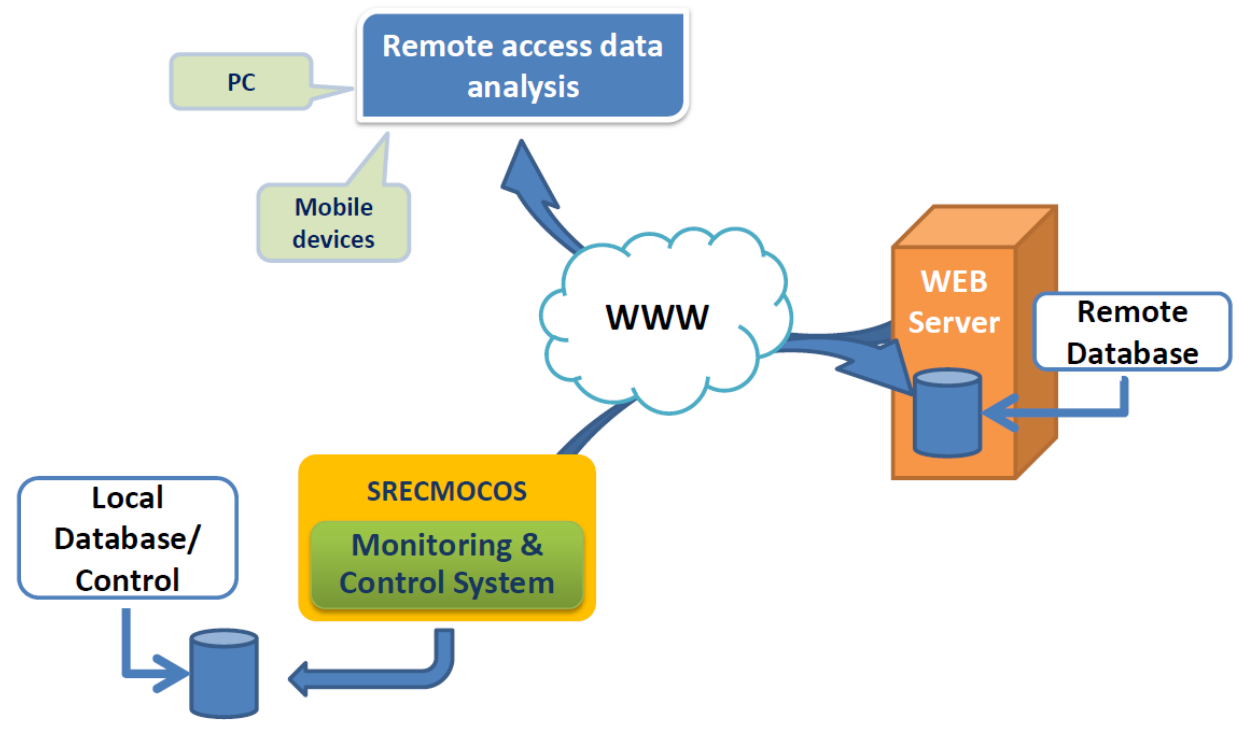

Figure 5. Internet based data management module. 
The monitoring and control system is connected to the data management tool via bluetooth, therefore no false constraints are imposed to the floating gate simulator. The monitored variables are exactly those obtained during field campaigns. The operator can also control the same actuators as in prototype (winch force on mooring lines and ballast level), this is achieved by means of two user interfaces which allow the operator to monitor winch and water ballast level in a computer (figure 6) as well as control the operation with a real switch console similar to the one in prototype.

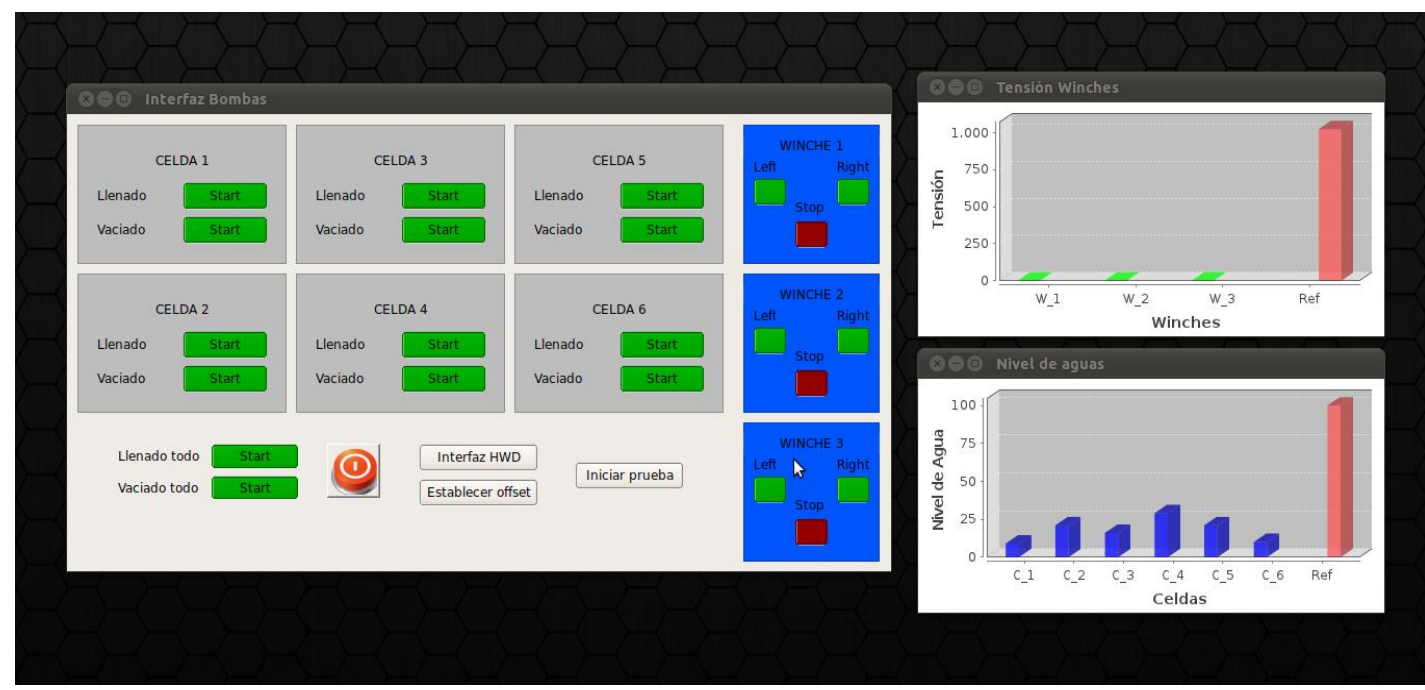

Figure 6.GUI showing (on the left box) water ballast control for each of the six different ballast cell in the gate as well as winch control. On the right a real time reading of winch tension (top) and ballast level

6. Operationality analysis and threshold establishment. After the simulator is properly calibrated, simulations can take place. The operation of the simulator is performed by the actual operator at prototype floating gate. This assures a proper reproduction of those agents derived from human interaction.

\section{CONCLUSSIONS}

- A global scaled simulator in which all the agents, constrains and responses are modeled has been implemented.

- $\quad$ The system is applicable to any other floating system with minor hardware adjustments

- The simulator is a very useful tool to identify and evaluate qualitatively and quantitatively failure modes on floating systems.

- The active participation of the prototype's operator has been very useful to calibrate de simulator. Even though time also has to be scaled and the gate's behavior is faster $(4,69$ times faster), only a short training was need.

\section{ACKNOWLEDGMENTS}

The authors are indebted to the Branch of Development and Research of the Public Organism of Ports of Spain and Astilleros Cernaval for partial support.

\section{REFERENCES}

Cabrerizo ,M 2007. Fondeo de cajones a grandes profundidades. Máster thesis. University of Granada (in Spanish)

Cabrerizo, M., R. Molina, C. Matutano and A. LLana. 2010. Control of porosity, reflection and transmisión coefficients using polymeric porous media and their application in testing physical 
models. Proceedings of 3rd International Conference on the Application of Physical Modelling to Port and Coastal Protection.

Chakrabarty,S.K., 1994. Offshore Structure Modeling. World Scientific.ISBN 981-02-1512-6

DELTARES 2008 project report H4762/Scale-model tests on caisson motions in waves and ballasting operation

Hughes, S.A., 1993. Physical models and laboratory techniques in coastal engineering. World Scientific. ISBN 981-02-1540-1

Losada, M.A., 2001 ROM 0.0 General procedure and requirements in the design of harbor and maritime structures. Part I. Puertos del Estado, Madrid. ISBN 84-88975-30-9

Matutano,C., M. Cabrerizo-Morales, R., Molina and F. de los Santos. 2011. Aplicación de técnicas de video imagen para la monitorización de elementos flotantes en áreas portuarias: Aplicación al dique compuerta del Astillero de Campamento. Proceedings of the 11th jornadas Españolas de Costas y Puertos (in Spanish)

Molina, R 2007. Resolución del problema geométrico en video imagen. Series monográficas CEAMA (in Spanish)

Terencio, M. 2011 Floating berth or the capability to express innovation and to remain competitive in today market. Port Technology International, 38, 100-1003 